\title{
Making Hope Happen
}

\author{
by Shane J. Lopez
}

Published by Atria Paperback, 2013. 260 pages.

\section{Reviewed by}

Alan Acosta (aacosta@fsu.edu), Florida State University

All too often, when people think about hope, they think about a feeling, an emotion, a warm, happy, optimistic outlook that makes people feel good about themselves. Hope is usually connected with the idea that if people believe in something hard enough, it will inevitably come true. Shane Lopez, author of Making Hope Happen, challenges the all too familiar conceptions and ideas people have of hope. Lopez invites readers to reframe their thinking about hope not as an emotion, but as a choice. He asserts that hope is a developmental process that can be learned and spread to others and is one of the most important lessons, if not the most important lesson, people can teach themselves and others.

Lopez breaks his discussion of hope into four major parts: "Thinking about the Future," "Choosing a Better Tomorrow," "Practicing the Three Hope Strategies," and "Creating a Network of Hope." In the first part, "Thinking about the Future," Lopez describes what hope is, why it is important, and what separates hope as a developmental process from the feeling with which it is often associated. "I realized that how we think about the future - how we hope - determines how well we live our lives" (p. 9). Lopez draws a clear distinction between actualized hope and the concept most people associate with the idea of hope, which is wishing. Hope is when people see goals of where they want to be, recognize that there are multiple ways to get there, that the path to those goals will not be obstacle free, and that people must take action and be intrinsically motivated in finding the pathways and overcoming the obstacles to achieve them. Wishing, however, is when people expect or want their goals to happen without doing anything or taking any action, instead relying on unseen or unknown forces to make them happen.

Lopez describes the hope development process as "The Hope Cycle" (p. 25). The Hope Cycle starts with the Present Self. The Present Self has a Future Self that it wants to become. The Present Self identifies specific goals that will get the Present Self to the Future Self. These goals are not just simplistic, everyday goals that people think about, such as "I want to get a degree." It is deeper than any traditional goal setting that people think about when coming up with goals, such as "I will be more thankful in my life." "Hope is built from the goals that matter most to us, that we come back to again and again, and that fill our minds with pictures of the future" (p. 24). Once the Present Self has identified its goals, it uses multiple pathways to get to the goals, monitors progress over time, and carries people forward. This gives one the agency and ability to shape life every day and 
propels one to identify more goals and another Future Self to work toward.

In "Choosing a Better Tomorrow," Lopez discusses in depth the process for identifying goals to get one from the Present Self to the Future Self. He identifies all of the potential barriers and problems that can come with setting up goals that do not generate hope. He also talks about how to see and think about the future in a way that is not beholden to the past. Lopez also identifies the three hope strategies. "Futurecasting" is the concept of visualizing the future people want for themselves and understanding what it looks like. "Triggering Action" is using the agency or ability that one has to start finding the pathways or methods to achieve those hopeful goals. "Planning for Ifs" means identifying what the potential obstacles are to achieving those goals so that one can figure out systems and ways to deal with and leave behind those obstacles.

In "Practicing the Three Hope Strategies," Lopez takes each of the three hope strategies previously identified and breaks them down into simple, manageable pieces to understand. He also does an excellent job of giving practical advice and action steps for people to follow, such as websites to visit, products to consider, and other printed resources that will assist individuals in going through the hopedevelopment process.

Lopez wraps up the book with the final section called "Creating a Network of Hope," in which he discusses how people can not only incorporate hope into their everyday lives, but also how to teach hope and the hope-development process to others. He also shares how people can build relationships with other individuals, as well as how to increase others' agency and capacity for hope.

Lopez's book is an excellent overall contribution to the higher education literature and would make an excellent common read. He frames hope in a very easy to understand way. He also uses a variety of styles to help him teach readers about the concepts he discusses. Some of the styles he uses includes stories from his clinical practice, examples from the news, and also research from the field of psychology. While the writing is not very technical or filled with psychological terminology, it is very easy to see how rooted in research many of his concepts are; the "Appendix" and "Notes" section of his book are extensive and point to all of the references he makes in the book. The book is also very well laid out, with each chapter building to the next one. While it can be a quick read, each page is filled with ideas and information that the reader will be able to utilize in both a personal and professional fashion. Anyone who reads this book will find something to take away and use in daily life.

The chapter of the book that will be most relevant for higher education professionals, as it will have ideas for programs and initiatives that can be utilized on campus, is "Teaching Hope to the Next Generation of Students." In this chapter, Lopez makes the argument that teaching hope to students, both in college and in higher education, will have a profound impact on their educational experience, and as a result, society at large. While many professionals who are well versed in recruitment and retention efforts at most institutions might be aware of many of the resources mentioned by Lopez, there are many higher education professionals who will learn new ideas. 
This chapter might also spur thoughts for ways to use this book if it were a common read into a campus project. From mentoring opportunities, to goal setting or hope workshops, campuses could use this book as a way to start a dynamic hope initiative on campus. Some potential resources and ideas include mentoring opportunities between high schools and higher education, revamping career days in the career center, doing more project-based or service learning in a campus's leadership department, helping students understand the actual costs of college, and bridging high school and higher education. These ideas, while not necessarily new, are backed in research and will resonate with higher education professionals passionate about increasing student hope and success in college.

While there are many good contributions of the book, it did have some weak points. While Lopez makes a compelling case for how hope is not just simplistic goal setting, it becomes reminiscent of traditional goal setting that has become commonplace. Also, while there is a section of the book dedicated to some practical suggestions on initiating the Hope Cycle, this part of the book is quite small when compared to the rest of the text. Lopez could have provided more practical examples for how to work the hope process and make the abstract ideas more tangible. One final missing component is the book never addresses how individuals with mental, emotional, behavioral, or psychological issues may have to modify how they approach the Hope Cycle. This was actually somewhat surprising, as Lopez is a psychologist, and one would assume that would be an area of expertise for him.

There are numerous audiences for Lopez's work. The book comes from the positive psychology canon, so the book would easily speak to mental health professionals and on-campus counseling centers. The book also has pieces with great implications for professionals that work in leadership and service, career services, student conduct, housing and residence life, and campus recreation. The book also will be relevant for any higher education professional seeking to critically examine how they approach their work and how they seek to impact student learning.

Making Hope Happen has interesting ideas and provides a unique, creative perspective on helping students to achieve their goals. By assisting students in increasing their hope, higher education professionals can make students more academically and personally successful. This practice also might make our institutions a more hopeful place to be for students, faculty, administrators, and staff. 